\title{
Men's psychological well-being during COVID-19: the moderator role of posttraumatic growth
}

\author{
Martim Santos ${ }^{1}$, Ana Mónica Machado ${ }^{1}$, Ana Cristina Bernardo ${ }^{1}$, Ângela Leite ${ }^{2}$, \\ M. Graça Pereira ${ }^{1, \star}$ \\ ${ }^{1}$ Research Center in Psychology (CIPsi), School of Psychology, University of Minho, 4710-057 Braga, Portugal \\ ${ }^{2}$ School of Human and Social Sciences, University of Tràs-os-Montes and Alto Douro, 5000-801 Vila Real, Portugal \\ *Correspondence: gracep@psi.uminho.pt (M. Graça Pereira)
}

\begin{abstract}
Background and objective: Men are significantly affected by COVID-19 stressors that impact psychological well-being. The purpose of this study was to examine the relationships between distress, risk perception, emotional representations, preventive COVID-19 infection behaviors, COVID19 traumatic stress, posttraumatic growth, and psychological well-being, taking also into consideration sociodemographic variables as well as the moderator role of posttraumatic growth in the relationship between traumatic stress and psychological well-being.
\end{abstract}

Material and methods: A cross-sectional design was used. Data were collected during the lockdown, in Portugal, from January to March 2021. The sample included 220 men who answered the questionnaires online.

Results: Anxiety and depression symptoms (distress), traumatic stress, and emotional representations were negatively associated with psychological well-being. Older men, professionally active men, and men not in teleworking reported greater psychological well-being. The findings also showed that less emotional representations, less traumatic stress, and lower levels of distress contributed to greater psychological well-being. Finally, posttraumatic growth played a moderating role in the relationship between traumatic stress and psychological well-being.

Conclusion: Interventions and further studies must consider the buffering role of posttraumatic growth during the COVID-19 pandemic and focus on helping men handle the associated traumatic stress in order to promote psychological well-being.

\section{Keywords}

Psychological well-being; Posttraumatic growth; Men; COVID-19; Traumatic stress; Distress; Emotional representations; Risk perception; Preventive infection behaviors

\section{Introduction}

The COVID-19 pandemic, which was declared on January 30th, 2020 by the World Health Organization (WHO), is considered a public health emergency of international concern [1]. In Portugal, the first cases of the disease were recorded on March 2nd, 2020 [2]. Also, more than 128 million cases related to COVID-19 were confirmed, the mortality stands now above two million, and nearly 547 million vaccine doses have been administrated worldwide [1].

There is several ongoing research due to the impact of the COVID-19 outbreak on health outcomes [3]. The vast majority of the existing evidence does not focus on men's health, particularly because the prevalence of the disease is similar in both genders; however, the risk of morbidity and mortality is higher in men than in women $[4,5]$. In fact, men are significantly affected by COVID-19 stressors [6]. 
In line with these findings, men's higher vulnerability to experience severe manifestations of COVID-19 seems to be explained by a lower immune response triggered by preexisting chronic conditions (e.g., cardiovascular and respiratory diseases), smoking and alcohol consumption, and also by preventive health behaviors (e.g., mask-wearing and washing hands frequently), which are lower than in women [4]. Despite that, the evidence indicates that men revealed greater levels of psychological well-being and that pre-existing psychological conditions are negatively associated with psychological well-being [7].

\subsection{Illness perceptions and emotional reaction}

Threatening illness perceptions regarding COVID-19 seem to be a key contributor to pandemic progression and have a direct impact on the number of new cases since they are related to more preventive behaviors. Also, threatening perceptions vary according to cultural and individuals features (e.g., personal experience, prosocial values) $[8,9]$. Therefore, risk perception is a potential predictor of population protective behaviors, and previous studies showed that men reported lower levels of risk perception as a concern than do women [9].

Several studies underlined the perceived risk of Severe Acute Respiratory Syndrome (SARS) infection, or more recently SARS-CoV-2, to be positively associated with emotional distress and negatively with psychological well-being $[10,11]$.

During COVID-19, many studies found that individuals in early adulthood, experienced higher levels of anxiety and depressive symptoms (distress) compared to other age groups and higher severity of symptoms was associated with younger ages $[12,13]$. In sharp contrast, a study from Tian et al. [14] showed that individuals at advanced ages reported severe distress and, generally, older individuals felt more anxious due to the fear or suspicion of being infected by COVID-19. A study conducted in Portugal with 1280 participants during quarantine found that $7.6 \%, 9.1 \%$, and $9.3 \%$ of the sample, reported severe symptoms of depression, anxiety, and stress, respectively [15]. The previous study also found that factors related to lifestyle, living conditions, maintaining one's job (online or in a workplace) and no pre-existing psychological disorders were protective variables of psychological wellbeing [16].

The role of less threatening emotional representation regarding COVID-19 is also critical. In cases of chronic disease, threatening illness perceptions were systematically associated with attitudes and intentions towards adherence to preventive behaviors $[17,18]$ and, the latter towards psychological well-being [17]. During the current pandemic, Aqeel et al. [19] found a significant negative relationship between distress, mental health, and illness perception. Furthermore, a higher perception of threat featured by intrusive thoughts and feelings (e.g., fear, loneliness, uncertainty), predicts poorer psychological well-being [20]. In fact, with the COVID-19 outbreak, a large number of additional stressors, namely stress, depressive and anxiety symptoms, and intrusive thoughts and feelings, are difficult to cope with $[3,14,15,20]$.

\subsection{Trauma response}

Trauma is defined as an objective adverse incident that may generate noxious stress, according to three critical elements (i.e., events, effects, and experiences) [21]. Thus, the same traumatic event could be experienced in different ways and the individuals' responses will determine the degree of trauma $[9,22]$.

The continued exposure to the COVID-19 pandemic is considered a predictor of traumatic stress [23] as well as distress [14]. However, Aftyka et al. [24] claim that trauma may also be linked to positive outcomes, considering that the individuals' experience is based on a positive evaluation of previous traumatic events and, consequently, contributes to the mean-making of a new sense of life.

It is well documented that intense stress response during traumatic events (e.g., previous epidemics) may lead to a short or long-term negative impact on mental health [25], mainly on psychological well-being [3]. The salutogenic effects attributed to trauma exposure, known as posttraumatic growth (PTG), may vary considerably and depends on the degree of experienced exposure $[23,26]$. The PTG theory focuses on individuals' subjective changes, i.e., how their core beliefs or world perspectives are disturbed by a stressor event [26]. After a traumatic event, a positive psychological change reflects a greater life satisfaction, as well as new life opportunities, personal development, and recognition of one's capacities [27].

Recent studies found that PTG plays a moderator role in the relationship between adverse responses to trauma (e.g., posttraumatic stress) and quality of life $[28,29]$. Moreover, the results of a path analysis model showed that PTG had a direct impact on depression in survivors of SARS [10]. Indeed, traumatic stress symptoms impaired individuals' daily life and had a significant clinical impact on long-term physical health [30], which in turn was associated with lower psychological well-being $[3,7,10]$.

Men's responses to the current pandemic are still unclear and not fully known and there is a need to address men's health regarding COVID-19, particularly the contribution of illness perceptions, emotional reactions, and trauma response in order to design interventions to decrease the psychological consequences of COVID-19, promoting men's psychological well-being. To address the gaps in the literature this study aims to (1) analyze the relationships between PTG, traumatic stress, distress, illness perception, risk perception, and preventive COVID-19 infection behaviors, and psychological well-being; (2) examine the differences between psychological well-being according to sociodemographic variables (e.g., age, education, marital status, teleworking, layoff); (3) examine the contribution of psychological variables to psychological well-being; (4) evaluate the moderator role of PTG in the relationship between traumatic stress and psychological well-being. We hypothesized that: (H1) posttraumatic growth, less traumatic stress, lower distress, less 
emotional representations of illness, less risk perception, and more preventive COVID-19 infection behaviors will be associated with greater psychological well-being; (H2) men with less education, on teleworking, in layoff, not professionally active, single, and younger will report less psychological well-being; (H3) PTG, emotional representations, traumatic stress, and distress, will contribute to psychological wellbeing; and finally, (H4) PTG will moderate the relationship between traumatic stress and psychological well-being.

\section{Materials and methods}

\subsection{Participants}

This study included 220 men, recruited via social media (e.g., facebook) and the university institutional email where the study received ethical approval. Criteria for participant inclusion were: (1) living in Portugal; (2) age 18 or older; and (3) being male. The mean age was 33.88 ( $\mathrm{SD}=12.87)$, ranging from 18 to 81 years old. Of the total sample, 189 (85.9\%) were not infected with COVID-19. Less than half of the participants who were infected reported light and moderate physical symptoms, and only one participant considered their symptoms severe. The most common disease symptoms experienced were tiredness $(7.7 \%)$, headache $(7.3 \%)$, loss of smell (6.8\%), loss of taste (6.4\%), and difficulties in breathing (6.4\%). None of the participants infected with COVID-19 were hospitalized due to this disease and only 24 (10.9\%) lived with someone with COVID-19. Table 1 describes the sociodemographic characteristics.

\subsection{Instruments}

\subsubsection{Sociodemographic and clinical questionnaire}

This questionnaire was developed for the purpose of this study and assesses sociodemographic variables (e.g., age, teleworking, marital status, professional status, layoff, having children) and clinical variables (e.g., COVID-19 diagnosis and severity of symptoms).

\subsubsection{Psychological general well-being index (QGBEP-R)}

This instrument includes six items rated on a five-point Likert scale, ranging from "none of the time" (0) to "all of the time" (5) (e.g., "Have you been bothered by nervousness or your "nerves" during the past month?") [31, 32]. The total score of psychological well-being ranges between 0 to 30 , with higher scores indicating more psychological well-being. In the original version, Cronbach's alpha was 0.73 , and in the Portuguese version was 0.86 . In this study, Cronbach's alpha was 0.89 .

\subsubsection{Posttraumatic growth inventory-short form (PTGI-SF)}

This instrument includes five subscales, such as relating to others, new possibilities, personal strength, spiritual change, and appreciation of life $[33,34]$. The scale comprises 10 items scored on a six-point Likert-type scale, ranging from
(0) "I did not experience this change as a result of my crisis" to (5) "I experienced this change to a very great degree as a result of my crisis" (e.g., "I changed my priorities about what is important in life"). A high score indicates more posttraumatic growth. In the original version, Cronbach's alpha was 0.86 and in the Portuguese version was 0.88 . In this study, Cronbach's alpha was 0.90 .

\subsubsection{Brief illness perception questionnaire (IPQ-B)}

This instrument assesses six dimensions of illness representations: consequences, timeline, personal control, treatment control, identity and emotional representations grouped into emotional ( 2 items), cognitive (5 items), and comprehension (1 item) representations [35, 36]. This scale comprises nine items (e.g., "How well do you feel you understand your illness?"). The first eight items are scored on a 0 to 10 Likert scale with higher scores indicating more negative illness perception. The ninth item is an open question about the perceived cause of illness, in which participants list the three most important causal factors in their illness and were not used in the present study. In the original and in the Portuguese version, the instrument presented good test-retest reliability (Pearson correlations were $0.24-0.73$, and 0.42 0.70 , respectively). In this study, the cognitive subscale was below 0.60 and the same was true for the global scale $(0.40)$ and therefore, only the emotional representations subscale was used since presented an acceptable alpha (0.57) considering that includes only 2 items [37].

\subsubsection{Hospital anxiety and depression scale (HADS)}

This instrument measures distress and include two subscales: anxiety and depression with 14 items [38, 39]. The items are scored on a four-point Likert scale ranging from "never" (0) to "always" (3) (e.g., I feel tense or "wound-up"). Scores for each subscale range between 0 and 21 , and higher scores indicate higher anxiety and depression symptoms (distress). In the original version, Cronbach's alpha was 0.89 for the full scale. In the Portuguese version, Cronbach's alpha for the full scale was 0.87. In this study, Cronbach's alpha was 0.86 .

\subsubsection{Preventive COVID infection behaviors scale (PCIBS)}

This instrument evaluates how individuals perform preventive COVID-19 infection behaviors. The scale contains five items scored on a five-point Likert scale, ranging from "almost never" (1) to "almost always" (5) (e.g., "How often do you maintain at least 1 -meter distance between yourself and others?") [40, 41]. Higher scores indicate more preventive behaviors. In the original version, Cronbach's alpha was 0.82 . In the Portuguese version and the present study, after the confirmatory analysis, item 5 was excluded with coefficient omega being 0.60 [41].

\subsubsection{COVID-19 traumatic stress (TSC)}

This questionnaire has 11 items scored on a five-point Likert scale, ranging between "means not at all" (1) and "means very much" (5) (e.g., "I am afraid of the COVID-19”) [41, 42]. 
T A B L E 1. Sociodemographic characteristics of the sample.

\begin{tabular}{|c|c|c|}
\hline & & N (\%) \\
\hline Age & $\mathrm{M} \pm \mathrm{SD} ; \mathrm{Min}-\mathrm{Max}$ & $33.88 \pm 12.87 ; 18-81$ \\
\hline Gender & Male & $220(100.0)$ \\
\hline \multirow[t]{2}{*}{ Nationality } & Portuguese & $205(93.2)$ \\
\hline & Other & $15(6.8)$ \\
\hline \multirow[t]{2}{*}{ Living place/parish } & Urban & $165(75.0)$ \\
\hline & Rural & $55(25.0)$ \\
\hline \multirow[t]{6}{*}{ Living with } & Alone & $24(10.9)$ \\
\hline & Spouse & $97(44.1)$ \\
\hline & Children & $38(17.3)$ \\
\hline & Parents & $85(38.6)$ \\
\hline & Parents in law & $6(2.7)$ \\
\hline & Other & $20(9.1)$ \\
\hline \multirow[t]{2}{*}{ Marital status } & Single & $151(68.6)$ \\
\hline & In a relation & $69(31.4)$ \\
\hline \multirow[t]{2}{*}{ Children } & No & $157(71.4)$ \\
\hline & Yes & $63(28.6)$ \\
\hline \multirow[t]{4}{*}{ Children's age } & Till 5 years old & $17(7.7)$ \\
\hline & Between 6 and 15 & $20(9.1)$ \\
\hline & Between 16 and 18 & $6(2.7)$ \\
\hline & Above 18 years old & $33(15.0)$ \\
\hline \multirow[t]{2}{*}{ Education } & Without university studies & $68(30.9)$ \\
\hline & With university studies & $152(69.1)$ \\
\hline \multirow[t]{2}{*}{ Professional status } & Active & $175(79.5)$ \\
\hline & Inactive & $45(20.5)$ \\
\hline \multirow[t]{3}{*}{ Usually work at home } & Yes & $88(40.0)$ \\
\hline & No & $86(39.1)$ \\
\hline & No answer & $46(20.9)$ \\
\hline \multirow[t]{3}{*}{ Teleworking } & Yes & $89(40.5)$ \\
\hline & No & $20(9.1)$ \\
\hline & No answer & $111(50.5)$ \\
\hline Duration of teleworking (weeks) & $\mathrm{M} \pm \mathrm{SD} ; \mathrm{Min}-\mathrm{Max}$ & $41.65 \pm 74.67 ; 1-521$ \\
\hline \multirow[t]{3}{*}{ Layoff } & Yes & $13(5.9)$ \\
\hline & No & $161(73.2)$ \\
\hline & No answer & $46(20.9)$ \\
\hline Duration of layoff (weeks) & $\mathrm{M} \pm \mathrm{SD} ; \mathrm{Min}-\mathrm{Max}$ & $86.75 \pm 219.77 ; 1-521$ \\
\hline
\end{tabular}

M, Mean; SD, Standard Deviation.

The instrument assesses COVID-19 traumatic stress, and includes three subscales: (1) fear of future infection/death; (2) economic trauma, and (3) routine disturbance. In the original version, Cronbach's alpha for COVID-19 traumatic stress global scale was 0.88 . In the Portuguese version and the present study, after a confirmatory analysis, all items were kept. The coefficient omega was 0.79 for the global traumatic stress scale [41].

\subsubsection{Numerical risk perception scale}

This visual scale assesses an individual's perception of the risk of contracting COVID-19 [43, 44]. The scale consists of a single item (e.g., "What is your risk perception of contracting COVID-19?") scored on a scale of 0 to 10 , where scores from 0 to 2 correspond to low risk perception, 3 to 7 to moderate risk perception, and 7 to 10 to intense risk perception.

\subsection{Procedure}

This cross-sectional study was approved by the Ethics Committee for Research in Social and Human Sciences of the University of Minho, in Portugal (CEICSH 018/2021). Data were collected between January 29th, 2021, and March 8th, 2021. Participants answered the informed and free consent form according to Helsinki Declaration and The Oviedo Convention and were also informed about the security statement regarding the platform. The questionnaires took approximately 10 minutes to answer.

\subsection{Statistical analysis}

The quantitative data were analyzed using IBM SPSS ${ }^{\circledR}$ (Statistical Package for the Social Sciences), version 27.0 (IBM Corp, Armonk, NY, USA). In order to assess the relationship between psychological variables and psychological wellbeing were performed Pearson correlation analyses. To evaluate differences in psychological well-being, according to so- 
T A B L E 2. Correlations between psychological variables and psychological well-being.

\begin{tabular}{|c|c|c|c|c|c|c|c|}
\hline & 1 & 2 & 3 & 4 & 5 & 6 & 7 \\
\hline 1. Psychological well-being & 1 & & & & & & \\
\hline 2. Preventive Infection behaviors & -0.116 & 1 & & & & & \\
\hline 3. Risk perception & -0.053 & $0.226^{* *}$ & 1 & & & & \\
\hline 4. Distress & $-0.803^{* *}$ & 0.092 & 0.090 & 1 & & & \\
\hline 5. Posttraumatic growth & 0.007 & 0.113 & 0.097 & 0.035 & 1 & & \\
\hline 6. Traumatic stress & $-0.532^{* *}$ & $0.234^{* *}$ & $0.216^{* *}$ & $0.572^{* *}$ & $0.288^{* *}$ & 1 & \\
\hline 7. Emotional representations & $-0.451^{* *}$ & $0.179^{* *}$ & $0.167^{*}$ & $0.516^{* *}$ & $0.259^{* *}$ & $0.670^{* *}$ & 1 \\
\hline
\end{tabular}

ciodemographic variables (e.g., age, education, marital status, teleworking, layoff) a Student's $t$-Test was performed. The effect size was analyzed using Cohen's $d[45,46]$. A hierarchical multiple regression analysis (MRA) (enter method) was conducted to find which psychological variables contributed to psychological well-being. Variables were selected if they correlated with psychological well-being $(P<0.05)$ and the statistical assumptions were fulfilled. Since the purpose of this study was to analyze the single contributor of each variable, a hierarchical regression analysis was selected. Emotional representations were entered in the first block, traumatic stress in the second block, and distress in the third block. Finally, to analyze the moderating role of PTG in the relationship between traumatic stress and psychological wellbeing, the moderation assumptions were tested and since they were fulfilled, the Macro Process for SPSS, version 3.5, with the Johnson-Neyman (JN) technique was used. JN technique allows to determine the transition point in which PTG is enough to notice a difference in the relationship between traumatic stress and psychological well-being $(P<$ 0.05) [47].

\section{Results}

\subsection{Correlations between psychological variables and psychological well-being}

A negative association was found between distress ( $\mathrm{r}$ $=-0.803, P<0.01)$, traumatic stress $(\mathrm{r}=-0.532, P<$ $0.01)$, emotional representations $(\mathrm{r}=-0.451, P<0.01)$ and psychological well-being (Table 2). PTG, preventive infection behaviors and risk perception were not correlated with psychological well-being.

\subsection{Differences in psychological well-being according to age, professional status, teleworking, education, marital status, and layoff}

Older men reported greater psychological well-being ( $\mathrm{t}$ (218) $=2.80, P=0.006)$. Professional active men reported greater psychological well-being when compared to nonactive men (t $(218)=3.76, P<0.001)$. Also, men who were not in teleworking reported greater psychological well-being than those who were $(\mathrm{t}(107)=2.26, P=0.026)$ (Table 3$)$. No differences were found on education, marital status, and being on layoff.

\subsection{Psychological variables that contribute to psychological well-being}

Model 1 in the MRA was significant $(\mathrm{F}(1,218)=55.53 ; P<$ $0.001)$, explaining $20.3 \%$ of the variance. This model showed that emotional representations $(\beta=-0.451, \mathrm{t}=-7.45, P$ $<0.001)$ contributed to psychological well-being. When traumatic stress related to COVID-19 was added (Model 2), the total variance explained increased by $29.9 \%\left(\mathrm{R}^{2}=0.299\right.$, $\mathrm{F}(1,217)=29.793, P<0.001)$. In this model, traumatic stress related to COVID-19 $(\beta=-0.327, \mathrm{t}=-5.458, P<$ $0.001)$ also contributed to psychological well-being. Finally, after adding distress, Model 3 in the MRA was significant ( $F$ $(1,216)=220.148 ; P<0.001)$ and explained $64.8 \%$ of the variance. Thus, the final model showed that less emotional representations $(\beta=-0.451, \mathrm{t}=-7.452, P<0.001)$ less traumatic stress $(\beta=-0.327, \mathrm{t}=-5.458, P<0.001)$ and lower levels of distress $(\beta=-0.743, \mathrm{t}=-4.837, P<0.001)$ contributed to greater psychological well-being (Table 4).

\subsection{Posttraumatic growth as a moderator between traumatic stress and psychological well-being}

The model that tested the moderating role of PTG in the relationship between traumatic stress and psychological wellbeing was significant $(\mathrm{F}(3,216)=42.03, P<0.001, \beta=0.012$, 95\% CI $(0.0065,0.192), \mathrm{t}=4.0025, P<0.001)$, explaining $35 \%$ of the variance Thus, there was a negative relationship between traumatic stress and psychological well-being when PTG was high $(\beta=-0.3315,95 \%$ CI $(-0.4306,-0.2324), \mathrm{t}=$ $-6.5939, P<0.001)$ and low $(\beta=-0.6135,95 \% \mathrm{CI}(-0.7335$, $-0.4934), \mathrm{t}=-10.0728, P<0.001)$, but the relationship was more intense when PTG was low. The JN technique showed that traumatic stress was significantly correlated with psychological well-being when the standardized value of PTG was 24.29 below the mean $(\beta=-0.1606, P<0.050)$, and this was true for $98.64 \%$ of the sample (Fig. 1 ).

\section{Discussion}

Regarding the first goal (the relationships between PTG, traumatic stress, distress, illness perception, risk perception, and preventive COVID-19 infection behaviors, and psychological well-being), the hypothesis stated that posttraumatic growth, less traumatic stress, lower levels of distress, less threatening emotional representations towards COVID-19, 
T A B L E 3. Differences in psychological well-being according to age, professional status, teleworking, education, marital status, and layoff.

\begin{tabular}{|c|c|c|c|c|c|c|c|}
\hline & & \multicolumn{2}{|c|}{ Psychological well-being } & \multirow[b]{2}{*}{$\mathrm{t}$} & \multirow[b]{2}{*}{ df } & \multirow[b]{2}{*}{$P$} & \multirow[b]{2}{*}{ Cohen's d } \\
\hline & & M & SD & & & & \\
\hline \multirow[t]{2}{*}{ Age group } & $18-33$ & 17.23 & 5.67 & -2.80 & 218 & 0.006 & -0.40 (small) \\
\hline & $34-81$ & 19.54 & 6.13 & & & & \\
\hline \multirow[t]{2}{*}{ Professional status } & Active & 18.78 & 5.61 & 3.76 & 218 & $<0.001$ & 0.62 (moderate) \\
\hline & Non-active & 15.20 & 6.26 & & & & \\
\hline \multirow[t]{2}{*}{ Teleworking } & Yes & 17.99 & 5.44 & -2.26 & 107 & 0.026 & -0.56 (moderate) \\
\hline & No & 20.95 & 4.62 & & & & \\
\hline \multirow[t]{2}{*}{ Education } & No Univ. St. & 17.88 & 6.20 & -0.242 & 218 & 0.809 & -0.04 \\
\hline & Univ. St. & 18.09 & 5.81 & & & & \\
\hline \multirow[t]{2}{*}{ Marital Status } & Single & 17.98 & 5.55 & -0.174 & 218 & 0.862 & -0.03 \\
\hline & In a relation & 18.13 & 6.71 & & & & \\
\hline \multirow[t]{2}{*}{ Layoff } & Yes & 18.85 & 5.96 & 0.047 & 172 & 0.963 & 0.01 \\
\hline & No & 18.77 & 5.60 & & & & \\
\hline
\end{tabular}

M, Mean; SD, Standard Deviation; No Univ. St., No University Studies; Univ. St., University Studies.

T A B L E 4. Psychological variables that contribute to psychological well-being.

\begin{tabular}{|c|c|c|c|c|c|c|c|c|c|}
\hline \multirow{2}{*}{ Variables } & \multicolumn{3}{|c|}{ Model 1} & \multicolumn{3}{|c|}{ Model 2} & \multicolumn{3}{|c|}{ Model 3} \\
\hline & B & EP B & $ß$ & B & EPB & $ß$ & B & EP B & ß \\
\hline Emotional representations & -1.22 & 0.164 & -0.451 & -0.463 & 0.208 & -0.171 & 0.022 & 0.150 & 0.008 \\
\hline Traumatic stress & & & -0.317 & 0.060 & 0.060 & -0.013 & -0.088 & 0.045 & -0.113 \\
\hline Distress & & & & & & & -0.682 & 0.046 & -0.743 \\
\hline $\mathrm{R}^{2}$ ( $\mathrm{R}^{2}$ Adj. $)$ & \multicolumn{3}{|c|}{$0.203(0.199)$} & \multicolumn{3}{|c|}{$0.299(0.293)$} & \multicolumn{3}{|c|}{$0.653(0.648)$} \\
\hline $\mathrm{F}$ for change in $\mathrm{R}^{2}$ & \multicolumn{3}{|c|}{$55.53^{* *}$} & \multicolumn{3}{|c|}{$29.79^{* *}$} & \multicolumn{3}{|c|}{$220.14^{* *}$} \\
\hline
\end{tabular}

B, unstandardized regression coefficients; Adj., adjusted; ${ }^{*} P<0.05$; ${ }^{* *} P<0.01{ }^{* * *} P<0.001$.

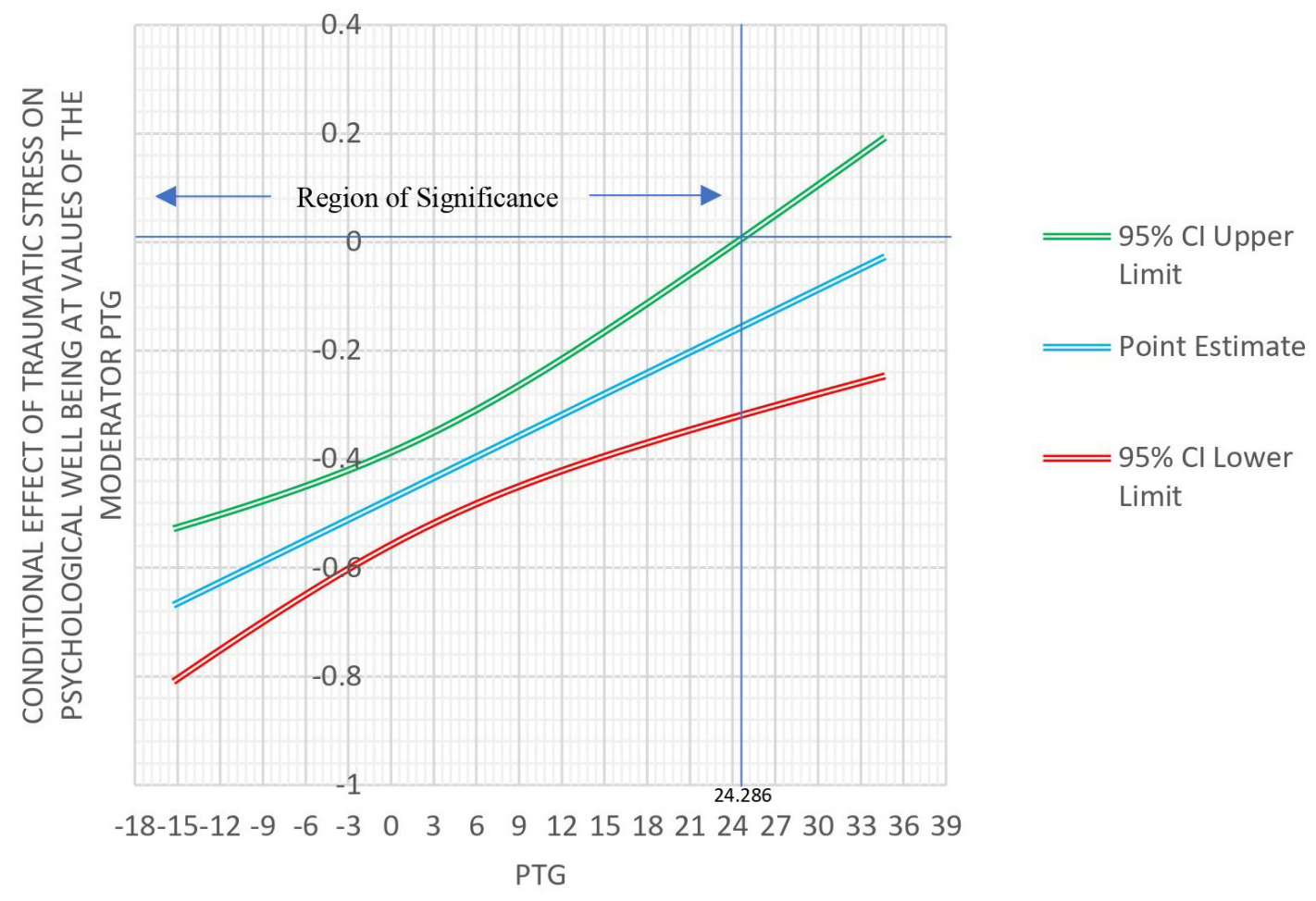

F IG. 1. Moderating role of PTG in the relationship between traumatic stress and psychological well-being.

less risk perception, and more preventive COVID-19 infection behaviors would be associated with greater psycholog- ical well-being (H1). The results showed that distress was negatively correlated with psychological well-being, which is 
corroborated by the literature indicating that, not only, more depression and anxiety are associated with less psychological well-being [7], but also have a long-lasting effect on overall well-being [48]. There was also a negative association between traumatic stress and psychological well-being. In fact, besides the severe health problems, exposure to the virus is recognized as a traumatic event [23]. The stress response during traumatic events may lead to a negative impact on mental health [25] and consequently, on psychological wellbeing [3]. As previously mentioned, the continued exposure to the COVID-19 pandemic is considered a predictor of traumatic stress [23] as well as distress [14]. This is consistent with prior research, that shows that while social distancing may contribute to a feeling of safety, it may also increase one's feelings of isolation, stress, and frustration, causing difficulties in many daily life situations [49], with a lasting effect on overall well-being [48].

More threatening emotional representations of COVID19 correlated negatively with psychological well-being. Regarding COVID-19, threatening emotional representations were associated with attitudes and intentions towards adherence to preventive behaviors [17,20], and therefore, with less psychological well-being [17].

Posttraumatic growth did not correlate with psychological well-being, perhaps because growth takes time to consolidate [50] and since the pandemic is not over, it is natural that participants do not report, as a result of their experience, any kind of positive transformation.

Higher risk perception was associated with more preventive behaviors and traumatic stress which is in line with Dryhurst et al. [9] as well as with emotional representations, as expected. The literature shows that risk perception has been related to specific negative emotions such as anxiety, depression, exhaustion, loneliness, and boredom [51], which in turn predict poorer psychological well-being [20]. Therefore, the hypothesis was partially confirmed.

Concerning the second goal, the second hypothesis stated that men with less education, on teleworking, in layoffs, not professionally active, single, and younger would report less psychological well-being. Results showed that older men presented more psychological well-being. In fact, it has been previously suggested that younger age increased negative mental health outcomes, including a range of psychiatric symptoms and stress in prior pandemics [52].

The results of the present study may be explained by the fact that the sample consisted mostly of men with an average age of 34 years old. However, reports on age as a risk factor for poor well-being are inconsistent $[53,54]$.

Results also showed differences in psychological wellbeing regarding the professional status with active men reporting more psychological well-being. This result is not in line with Möhring et al. [55] who found a pronounced decrease in well-being in the aftermath of the lockdown, but the decrease could not be attributed to any specific change in the employment situation. The COVID-19 outbreak places various challenges on individuals [10] and, as a result, professional status was one of the aspects most affected by the pandemic. In fact, in this study, being active seemed to be a protective factor. Future studies should pursue this hypothesis.

Men who were not teleworking reported more psychological well-being than men who were. These results are in accordance with Song and Gao [56]. In fact, the effect of working at home on subjective well-being depends on parental status and gender. Parents, especially fathers, reported a lower level of subjective well-being when working at home. On the contrary, Anderson et al. [57] found that employees experienced more job-related positive affective well-being on the days they were teleworking compared to the days they were working in the office.

In this study, marital status, education, and layoff did not impact well-being, contrary to the initial hypothesis. In fact, some authors found mixed results suggesting that the continuously married present better well-being (e.g., less depression, better positive relationships with others, and better sense of purpose in life) than the formerly married and the never-married; however, results regarding other positive outcome measures, besides wellbeing, indicate that the unmarried, and the remarried fare better than the continuously married, namely greater autonomy, higher environmental mastery, and personal growth than the remarried or nevermarried [58]. Concerning education, mixed results have also been found: Jongbloed [59] found that the impact of education is significantly different when well-being is defined from a eudaimonic and hedonic perspective; the author also found that although education is not significantly associated with satisfaction with life of women and men, it is significantly associated with the extent to which both men and women are flourishing in their lives. Regarding layoff, the results may be explained by the characteristics of the present sample that was, for the most part, single with higher education and not in layoff, which may have biased the results. Therefore, the hypothesis was partially confirmed. Future studies should include marital status, education, being or not in layoff and assess how these variables impact wellbeing, over time.

Regarding the contribution of psychological variables to psychological well-being, the third hypothesis stated that PTG, emotional representations, traumatic stress, and distress, would contribute to psychological well-being. The results showed that emotional representations, traumatic stress related to COVID-19, and distress contributed to psychological well-being. However, distress contribution was more significant than emotional representations and traumatic stress. The literature presents several predictors of psychological well-being, namely, depression [60, 61] and anxiety [60, 62]. Indeed, lower levels of anxiety and depression have a huge impact on well-being [63]. The results showed that emotional representations also contributed to psychological wellbeing. This is in line with Mondragon et al. [64], that found that emotional representation, in university students, to face the first outbreak of the COVID-19 pandemic, negatively affected their well-being. In addition, traumatic stress also contributed to explain psychological well-being. In fact, the COVID-19 pandemic is considered a predictor of traumatic 
stress [23], and traumatic stress predicts negative well-being [3]. Therefore, the hypothesis was partially confirmed.

Finally, regarding the moderating role of PTG in the relationship between traumatic stress and psychological wellbeing, the hypothesis stated that PTG would moderate the relationship between traumatic stress and psychological wellbeing. The findings revealed that PTG played a moderator role between traumatic stress and psychological well-being. Therefore, PTG refers to post-event changes rather than individuals' responses during an event and those changes have significant behavioral repercussions and may become truly growing experiences [26]. In fact, the COVID-19 pandemic is associated with factors that may account for the increase of extreme anxiety and helplessness [65]. However, in addition to the negative impact of overwhelming events, individuals may also experience positive transformations (PTG) resulting from coping with adverse life events, that possibly buffer the impact of negative outcomes [66] and, consequently, is associated with psychological well-being. This result confirms that the PTG theory proposed by Aftyka et al. [24] could be applied to the current pandemic situation in men. More specifically, trauma may be linked to positive outcomes because the individuals' experience is based on a positive evaluation of previous traumatic events, contributing to a new sense of life. Therefore, the hypothesis was fully confirmed.

This study has some limitations that should be acknowledged, in particular, the sample size (which is not representative of the male population), the use of self-report measures, as well as the cross-sectional design of the study that does not allow causal inferences. Further research should use a longitudinal design and include Structural Equation Modeling (SEM) analysis, particularly latent curve modeling to understand how men's psychological well-being changes, over time, as a result of the pandemic experience, particularly PTG. Also, a comparative study between men and women is warranted including how coping variables (e.g., optimism, spirituality, hope) may also play a moderator role.

\section{Conclusions}

The COVID-19 pandemic, a public health emergency of international concern, impacts an individual's psychological well-being, causing several disturbances in daily life. The results of the present study underline the need for interventions to focus on the prevention, monitorization, and treatment of anxiety and depression, towards the promotion of psychological well-being, since these variables contributed the most to psychological well-being.

Overall, the moderating role of PTG, in the relationship between traumatic stress and psychological well-being, confirms the importance of posttraumatic growth, particularly for men during the COVID-19 outbreak. Thus, interventions and further studies must consider the buffering role of PTG during the COVID-19 pandemic and future traumatic events. In order to foster personal posttraumatic growth, it is important to help individuals handle traumatic stress, particularly the pain and suffering beneath, since it lays the groundwork for change and gives individuals a sense of agency towards their future [67].

\section{Author contributions}

MS: Manuscript preparation, writing, data analysis, data interpretation, and manuscript review. AMM: Data management and data analysis. ACB: Data acquisition, manuscript preparation, writing, and editing. ÂL: Data interpretation, writing, and manuscript review. MGP: Study design, manuscript preparation, data interpretation, manuscript review, editing, and revising it critically for important intellectual content.

\section{Ethics approval and consent to participate}

This study was approved by the Ethics Committee for Research in Social and Human Sciences of the University of Minho, Braga, Portugal with the number: CEICSH 018/2021. All participants gave their informed consent for inclusion before they participated in the study.

\section{Acknowledgment}

The authors want to thank all participants for their contribution to the present study.

\section{Funding}

This research received no external funding.

\section{Conflict of interest}

The authors declare no conflict of interest.

\section{References}

[1] World Health Organization. Coronavirus disease (COVID-19) pandemic. 2021. Available at: https : / www . who. int/emergencies/ diseases/novel-coronavirus-2019 (Accessed: 2 April 2021).

[2] General Director of Health. New Coronavirus COVID-19. 2020. Available at: https://covid19.min-saude.pt/ponto-desituacao-atual-em-portugal/ (Accessed: 2 April 2021).

[3] Torales J, O'Higgins M, Castaldelli-Maia JM, Ventriglio A. The outbreak of COVID-19 coronavirus and its impact on global mental health. International Journal of Social Psychiatry. 2020; 66: 317-320.

[4] Betron M, Gottert A, Pulerwitz J, Shattuck D, Stevanovic-Fenn N. Men and COVID-19: Adding a gender lens. Global Public Health. 2020; 15: 1090-1092.

[5] Global Health 5050. The COVID-19 sex-disaggregated data tracker. 2021. Available at: https : / globalhealth5050 .org/the-sexgender-and-covid-19-project/ (Accessed: 15 March 2021).

[6] Gebhard C, Regitz-Zagrosek V, Neuhauser HK, Morgan R, Klein SL. Impact of sex and gender on COVID-19 outcomes in Europe. Biology of Sex Differences. 2020; 11: 29.

[7] O'Connor RC, Wetherall K, Cleare S, McClelland H, Melson AJ, Niedzwiedz CL, et al. Mental health and well-being during the COVID19 pandemic: longitudinal analyses of adults in the UK COVID-19 Mental Health \& Wellbeing study. The British Journal of Psychiatry. 2020; 218: 326-333.

[8] Cori L, Bianchi F, Cadum E, Anthonj C. Risk Perception and COVID19. International Journal of Environmental Research and Public Health. 2020; 17: 3114. 
[9] Dryhurst S, Schneider CR, Kerr J, Freeman ALJ, Recchia G, van der Bles AM, et al. Risk perceptions of COVID-19 around the world. Journal of Risk Research. 2020; 23: 994-1006.

[10] Cheng SKW, Chong GHC, Chang SSY, Wong CW, Wong CSY, Wong MTP, et al. Adjustment to severe acute respiratory syndrome (SARS): Roles of appraisal and post-traumatic growth. Psychology \& Health. 2006; 21: 301-317.

[11] Lanciano T, Graziano G, Curci A, Costadura S, Monaco A. Risk Perceptions and Psychological Effects During the Italian COVID-19 Emergency. Frontiers in Psychology. 2020; 11: 580053.

[12] Huang Y, Zhao N. Generalized anxiety disorder, depressive symptoms and sleep quality during COVID-19 outbreak in China: a web-based cross-sectional survey. Psychiatry Research. 2020; 288: 112954.

[13] Ozamiz-Etxebarria N, Dosil-Santamaria M, Picaza-Gorrochategui M, Idoiaga-Mondragon N. Stress, anxiety, and depression levels in the initial stage of the COVID-19 outbreak in a population sample in the northern Spain. Cad Saude Publica. 2020; 36: e00054020.

[14] Tian F, Li H, Tian S, Yang J, Shao J, Tian C. Psychological symptoms of ordinary Chinese citizens based on SCL-90 during the level i emergency response to COVID-19. Psychiatry Research. 2020; 288: 112992.

[15] Silva Moreira P, Ferreira S, Couto B, Machado-Sousa M, Fernández M, Raposo-Lima C, et al. Protective elements of mental health status during the COVID-19 outbreak in the Portuguese population. International Journal of Environmental Research and Public Health. 2021; 18: 1910.

[16] Pereira MG, Ferraz A, Bernardo AC, Machado AM, Evangelista M, Ribeiro I, et al. Family Functioning during COVID-19 in Portugal: Does Hope Matter? 2021.

[17] Lee Y, Baek J, Jeon Y, Im E. Illness perception and sense of well-being in breast cancer patients. Patient Preference and Adherence. 2019; 13: 1557-1567.

[18] Pereira MG, Pedras S, Machado JC, Ferreira G. Partners' representations of diabetes as mediators between patients' representations and adherence to self-care behaviors, in type 2 diabetes. Psychology, Health \& Medicine. 2016; 21: 707-714.

[19] Aqeel M, Shuja KH, Abbas J, Rehna T, Ziapour A. The Influence of Illness Perception, Anxiety and Depression Disorders on Students Mental Health during COVID-19 Outbreak in Pakistan: A WebBased Cross-Sectional Survey; Research Square. 2020. Available at: https://www.researchsquare.com/article/rs-30128/ v1 (Accessed: 16 March 2021).

[20] Paredes MR, Apaolaza V, Fernandez-Robin C, Hartmann P, YañezMartinez D. The impact of the COVID-19 pandemic on subjective mental well-being: the interplay of perceived threat, future anxiety and resilience. Personality and Individual Differences. 2021; 170: 110455.

[21] Anda RF, Porter LE, Brown DW. Inside the Adverse Childhood Experience Score: Strengths, Limitations, and Misapplications. American Journal of Preventive Medicine. 2020; 59: 293-295.

[22] Griffin G. Defining trauma and a trauma-informed COVID-19 response. Psychological Trauma. 2020; 12: S279-S280.

[23] Lv Z, Yang J, Jiang H, Nan J. Psychological impacts of the COVID19 epidemic on Chinese people: Exposure, post-traumatic stress symptom, and emotion regulation. Asian Pacific Journal of Tropical Medicine. 2020; 13: 252.

[24] Aftyka A, Rozalska I, Milanowska J. Is post-traumatic growth possible in the parents of former patients of neonatal intensive care units? Annals of Agricultural and Environmental Medicine. 2020; 27: 106112.

[25] Wu P, Fang Y, Guan Z, Fan B, Kong J, Yao Z, et al. The Psychological Impact of the SARS Epidemic on Hospital Employees in China: Exposure, Risk Perception, and Altruistic Acceptance of Risk. The Canadian Journal of Psychiatry. 2009; 54: 302-311.

[26] Tedeschi RG, Shakespeare-Finch J, Taku K, Calhoun LG. Posttraumatic growth: Theory, research, and applications. Routledge. 2018; 131-138.

[27] Tedeschi RG, Calhoun, LG. Posttraumatic growth: Conceptual foundations and empirical evidence. Psychological Inquiry. 2004; 15: $1-18$.
[28] Martz E, Livneh H, Southwick SM, Pietrzak RH. Posttraumatic growth moderates the effect of posttraumatic stress on quality of life in U.S. military veterans with life-threatening illness or injury. Journal of Psychosomatic Research. 2018; 109: 1-8.

[29] Morrill EF, Brewer NT, O'Neill SC, Lillie SE, Dees EC, Carey LA, et al. The interaction of post-traumatic growth and post-traumatic stress symptoms in predicting depressive symptoms and quality of life. Psycho-Oncology. 2008; 17: 948-953.

[30] Ferry FR, Brady SE, Bunting BP, Murphy SD, Bolton D, O’Neill SM. The Economic Burden of PTSD in Northern Ireland. Journal of Traumatic Stress. 2015; 28: 191-197.

[31] Grossi E, Groth N, Mosconi P, Cerutti R, Pace F, Compare A, et al. Psychological General well-being Index-Short Version. Health and Quality of Life Outcomes. 2006; 4.

[32] Barroso I, Antunes M, Barroso I, Correia T, Brito I, Monteiro M. Adaptation and validation of the Psychological General well-being Index: confirmatory factor analysis of the short version. Revista De Enfermagem Referência. 2018; IV Série: 9-18.

[33] Cann A, Calhoun LG, Tedeschi RG, Taku K, Vishnevsky T, Triplett $\mathrm{KN}$, et al. A short form of the Posttraumatic Growth Inventory. Anxiety, Stress \& Coping. 2010; 23: 127-137.

[34] Lamela D, Figueiredo B, Bastos A, Martins H. Psychometric Properties of the Portuguese Version of the Posttraumatic Growth Inventory Short Form among Divorced Adults. European Journal of Psychological Assessment. 2014; 30: 3-14.

[35] Broadbent E, Petrie KJ, Main J, Weinman J. The brief illness perception questionnaire. Journal of Psychosomatic Research. 2006; 60: 631-637.

[36] McIntyre T, Araújo-Soares V, Trovisqueira A. Questionário de Crenças sobre a Doença - Versão Breve. 2004. Available at: http: //www . uib.no/ipq/ (Accessed: 20 March 2021).

[37] Taber KS. The Use of Cronbach's Alpha when Developing and Reporting Research Instruments in Science Education. Research in Science Education. 2018; 48: 1273-1296.

[38] Zigmond AS, Snaith RP. The hospital anxiety and depression scale. Acta Psychiatrica Scandinavica. 1983; 67: 361-370.

[39] Pais-Ribeiro J, Silva I, Ferreira T, Martins A, Meneses R, Baltar M. Validation study of a Portuguese version of the Hospital Anxiety and Depression Scale. Psychology, Health \& Medicine. 2007; 12: 225-227.

[40] Chang KC, Hou WL, Pakpour AH, Lin CY, Griffiths MD. Psychometric Testing of Three COVID-19-Related Scales Among People with Mental Illness. International Journal of Mental Health and Addiction. 2020; 1-13.

[41] Leite A, Almeida, AC, Pereira, MG. Portuguese Version of COVID-19 Traumatic Stress and Preventive COVID Infection Behaviors Scale in Portuguese Men during Covid-19. Health \& Family Research Group, School of Psychology, University of Minho. 2020.

[42] Kira IA, Shuwiekh HAM, Rice KG, Ashby JS, Elwakeel SA, Sous MSF, et al. Measuring COVID-19 as Traumatic Stress: Initial Psychometrics and Validation. Journal of Loss and Trauma. 2020; 26: 220-237.

[43] Crump S. Hypertension Risk Perception, Hypertension Knowledge, and Health Value as Predictors of Health Promotion Behaviors in African American College Students. Howard University. 2010.

[44] Pereira MG, Pereira A. Validação das escalas de perceção de risco da hipertensão e importância atribuída à saúde. Revista da Sociedade Brasileira de Psicologia Hospitalar. 2013; 16: 137-15216. (In Portuguese)

[45] Cohen J. Statistical Power Analysis for the Behavioral Sciences. New York: Routledge. 1988.

[46] Cohen J. A power primer. Psychological Bulletin. 1992; 112: 155-159.

[47] Johnson PO, Fay LC. The Johnson-Neyman technique, its theory and application. Psychometrika. 1950; 15: 349-367.

[48] Kang L, Li Y, Hu S, Chen M, Yang C, Yang BX, et al. The mental health of medical workers in Wuhan, China dealing with the 2019 novel coronavirus. The Lancet Psychiatry. 2020; 7: e14.

[49] Levkovich I, Shinan-Altman S. Impact of the COVID-19 pandemic on stress and emotional reactions in Israel: a mixed-methods study. International Health. 2020; 1. 
[50] Tedeschi RG, Calhoun LG. A Clinical Approach to Posttraumatic Growth. Positive Psychology in Practice. 2012; 405-419.

[51] Han Q, Zheng B, Agostini M, Bélanger JJ, Gützkow B, Kreienkamp $\mathrm{J}$, et al. Associations of risk perception of COVID-19 with emotion and mental health during the pandemic. Journal of Affective Disorders. 2021; 284: 247-255.

[52] Kamigaki $\mathrm{T}$, Oshitani H. Influenza pandemic preparedness and severity assessment of pandemic (H1N1) 2009 in South-east Asia. Public Health. 2010; 124: 5-9.

[53] Huang C, Wang Y, Li X, Ren L, Zhao J, Hu Y, et al. Clinical features of patients infected with 2019 novel coronavirus in Wuhan, China. The Lancet. 2020; 395: 497-506.

[54] Mazza C, Ricci E, Biondi S, Colasanti M, Ferracuti S, Napoli C, et al. A nationwide survey of psychological distress among Italian people during the COVID-19 pandemic: immediate psychological responses and associated factors. International Journal of Environmental Research and Public Health. 2020; 17: 3165.

[55] Möhring K, Naumann E, Reifenscheid M, Wenz A, Rettig T, Krieger U, et al. The COVID-19 pandemic and subjective well-being: longitudinal evidence on satisfaction with work and family. European Societies. 2020; 23: S601-S617.

[56] Song Y, Gao J. Does Telework Stress Employees out? a Study on Working at Home and Subjective well-being for Wage/Salary Workers. Journal of Happiness Studies. 2020; 21: 2649-2668.

[57] Anderson AJ, Kaplan SA, Vega RP. The impact of telework on emotional experience: when, and for whom, does telework improve daily affective well-being? European Journal of Work and Organizational Psychology. 2015; 24: 882-897.

[58] Hsu T, Barrett AE. The Association between Marital Status and Psychological well-being: Variation across Negative and Positive Dimensions. Journal of Family Issues. 2020; 41: 2179-2202.

[59] Jongbloed J. Higher education for happiness? Investigating the impact of education on the hedonic and eudaimonic well-being of Europeans. European Educational Research Journal. 2018; 17: 733-754.

[60] Galinha IC, Pais-Ribeiro JL. Cognitive, affective and contextual predictors of subjective well-being. International Journal of Wellbeing. 2012; 2: 34-53.

[61] Ridner SL, Newton KS, Staten RR, Crawford TN, Hall LA. Predictors of well-being among college students. Journal of American College Health. 2016; 64: 116-124.

[62] Mazzotti E, Mazzuca F, Sebastiani C, Scoppola A, Marchetti P. Predictors of existential and religious well-being among cancer patients. Supportive Care in Cancer. 2011; 19: 1931-1937.

[63] Gallagher MW, Smith LJ, Richardson AL, D’Souza JM, Long LJ. Examining the longitudinal effects and potential mechanisms of hope on COVID-19 stress, anxiety, and well-being. Cognitive Behaviour Therapy. 2021; 50: 234-245.

[64] Idoiaga Mondragon N, Berasategi Sancho N, Eiguren Munitis A, Dosil Santamaria M. Exploring the social and emotional representations used by students from the University of the Basque Country to face the first outbreak of COVID-19 pandemic. Health Education Research. 2021; 36: 159-169.

[65] Liu N, Zhang F, Wei C, Jia Y, Shang Z, Sun L, et al. Prevalence and predictors of PTSS during COVID-19 outbreak in China hardesthit areas: Gender differences matter. Psychiatry Research. 2020; 287: 112921.

[66] Lau JTF, Yang X, Tsui HY, Pang E, Wing YK. Positive mental healthrelated impacts of the SARS epidemic on the general public in Hong Kong and their associations with other negative impacts. The Journal of Infection. 2006; 53: 114-124.

[67] Paredes A, Pereira MG. Spirituality, Distress and Posttraumatic Growth in Breast Cancer. Journal of Religion \& Health. 2018; 57: 1606-1617. 